\title{
A flexible GPS tracking system for studying bird behaviour at multiple scales
}

\author{
Willem Bouten · Edwin W. Baaij • \\ Judy Shamoun-Baranes · Kees C. J. Camphuysen
}

Received: 2 June 2012/Revised: 27 October 2012/ Accepted: 31 October 2012/Published online: 28 November 2012

(C) The Author(s) 2012. This article is published with open access at Springerlink.com

\begin{abstract}
Tracking devices and bio-loggers provide crucial information on the ecology and behaviour of birds in their natural environment. An optimal tracking system should be lightweight, measure three-dimensional locations, enable flexible measurement schemes, transmit data remotely and measure environmental variables and biological parameters of the individual. Giving full consideration to the traits of birds and the constraints of technology, we have developed a GPS tracking system that attempts to achieve most of the aspirations of an optimal tracking system for free ranging birds without the need to recapture them. Here, we describe the design, performance and limitations of the system. We also present measurements on the tracked Lesser Black-backed Gull Larus fuscus to show how such a system can generate new opportunities for research at multiple scales. The GPS tracker weighs $12 \mathrm{~g}$ and includes a GPS receiver, micro-processor, $4 \mathrm{MB}$ of memory for data storage, solar panel and battery. It has a
\end{abstract}

Communicated by F. Bairlein.

Electronic supplementary material The online version of this article (doi:10.1007/s10336-012-0908-1) contains supplementary material, which is available to authorized users.

W. Bouten $(\bowtie) \cdot J$. Shamoun-Baranes

Computational Geo-Ecology, Institute for Biodiversity and Ecosystem Dynamics (IBED), University of Amsterdam, P.O. Box 94248, 1090 GE Amsterdam, The Netherlands e-mail: w.bouten@UvA.nl

E. W. Baaij

Science Faculty, Technology Centre, University of Amsterdam, P.O. Box 94216, 1090 GE Amsterdam, The Netherlands

K. C. J. Camphuysen

Royal Netherlands Institute for Sea Research (NIOZ),

P.O. Box 59, 1790 AB Den Burg, Texel, The Netherlands tri-axial accelerometer to monitor behaviour. To maximize flexibility, it is equipped with a radio transceiver for bidirectional communication with a ground-based antenna network, which enables data to be downloaded and new measurement schemes to be uploaded remotely. The system facilitates a multi-scale approach to studying bird movement, from fine-scale movements (3-s measurement intervals) to long-distance migratory movements (intervals of 20-30 min) of the same individual. We anticipate that flexible tracking systems that enable researchers to optimize their measurement protocols will contribute to revolutionizing research on animal behaviour and ecology in the next decade.

Keywords Accelerometer - Animal movement . Bio-logger · Migration · Flight strategy · Foraging

\section{Zusammenfassung}

Ein tragbares GPS-Tracking-Gerät mit großer MessBandbreite zur Untersuchung von Vogel-Verhalten

Tracking-Geräte und Apparate zur Aufzeichnung biologischer Daten liefern wichtige Informationen zu Ökologie und Verhalten von Vögeln in ihrer natürlichen Umgebung. Ein optimales Tracking-Gerät müsste sehr leicht sein, dreidimensionale Ortsangaben liefern, flexible Mess-Programme zulassen, Daten drahtlos übertragen sowie Umweltwerte und biologische Parameter individueller Tiere erfassen. Unter Berücksichtigung der Eigenheiten von Vögeln einerseits und der Einschränkungen technischer Apparaturen andererseits, haben wir ein GPS-TrackingGerät entwickelt und dabei versucht, möglichst viele der Anforderungen an ein optimales Gerät für freilebende Vögel zu realisieren, ohne die Tiere einfangen zu müssen. 
Wir beschreiben hier das Design, die Leistung und auch die Grenzen dieses Tracking-Geräts. Ferner präsentieren wir damit durchgeführte Messungen bei fern-verfolgten $\mathrm{He}$ ringsmöwen (Larus fuscus), um zu zeigen, wie solch ein Gerät neue Möglichkeiten für derartige Untersuchungen mit großer Mess-Bandbreite eröffnen kann. Das Gerät wiegt 12 Gramm und beinhaltet einen GPS-Empfänger, einen Mikroprozessor, $4 \mathrm{MB}$ Speicherplatz für Daten, eine Solarzelle und eine Batterie; ferner hat es einen drei-achsialen Beschleunigungsmesser zur Registrierung relevanter Verhaltensweisen. Um ein Höchstmaß an Flexibilität zu erzielen, ist es mit einem Sender/Empfänger für Zwei-Wege-Kommunikation ausgestattet, um über eine bodengestützten Antennenanlage das drahtlose Herunterladen von Messdaten und Heraufladen von neuen Mess-Programmen zu ermöglichen. Ferner realisiert das Gerät die Erfassung von Ortsveränderungen bei Vögeln in verschiedenen Messbereichen: von einem hoch auflösenden Bereich (Messintervalle von 3 Sekunden) bis zur Erfassung von Langstrecken-Bewegungen im Bereich von 20-30 Minuten beim selben Individuum. Wir denken, dass tragbare Tracking-Geräte Wissenschaftler helfen werden, ihre Messverfahren zu optimieren, was in den nächsten zehn Jahren zu ganz neuen Forschungsansätzen in Verhaltensforschung und Ökologie führen wird.

\section{Introduction}

The use of bio-loggers and tracking devices is allowing scientists to unveil the secrets of time use, movement, behaviour and ecology of free-living animals in ever more detail. Due to technological innovations the size and mass of animal-attached devices are decreasing, and the use of animal-attached devices to measure geographical position, body movements, physiological parameters and environmental variables is increasing. The numerous comprehensive reviews that have recently been published (Cooke et al. 2004; Ropert-Coudert and Wilson 2005; Wikelski et al. 2007; Rutz and Hays 2009; Cagnacci et al. 2010; Robinson et al. 2010; Tomkiewicz et al. 2010; Bridge et al. 2011; Guilford et al. 2011; Sokolov 2011) show that the development of tracking and bio-logging devices is a fastmoving field, catalysed by the drive of biologists to learn more about their study systems as well as by the on-going technological advances in wireless communication and personal navigation systems.

The trend towards miniaturization of electronics continuously generates new opportunities for developing trackers. Imagine an optimal tracking device if there were no technical constraints. The device carried by the bird should affect its behaviour as little as possible; this means that it would be light ( $<3 \%$ of body mass) and small with an optimized aerodynamic or hydrodynamic shape (Casper 2009). Once a bird is tagged, it would not be necessary to recapture the bird to recharge the battery, download the data or change a measurement scheme. The device would fall off when it is not functioning properly or when the research has come to an end. The device would work reliably for several years and produce accurate measurements throughout the research period. It would measure the geographical location and altitude, speed and direction, and include sensors to monitor behaviour, physiological characteristics such as heart rate and environmental conditions such as temperature or pressure, all at high resolution in time and space. Reliable data transmission while the bird is at any place in the world would facilitate real-time monitoring. Our imagined optimal tracking device would be easy to use and would cost almost nothing. To facilitate the efficient use of data, the device would be embedded in a dedicated system for data management and analysis.

The main challenge of our research was to design and create a GPS tracking system for free ranging birds that is as close as possible to the pareto optimum of most of the above-mentioned criteria. In this paper we share the choices we made in the design and our experience with the system. We present several tests which we used to determine the performance of the system and to identify the main limitations. We focus especially on the interaction and dynamics of power use by the GPS receiver and solar charging of the batteries. To show how a flexible tracking system generates new opportunities for multi-scale research, we also report several examples from ongoing tracking research.

\section{Methods}

\section{System design}

We developed our system with a broad range of research questions and study systems in mind. Most of these research questions relate to the flight strategies and spatial patterns of behaviour of free-ranging birds during breeding, while on migration and while at stopover or wintering areas. Our design was influenced by three main requirements. The first requirement was to avoid the need to recapture a bird. We therefore chose to develop a solar-powered device with bi-directional remote data transmission for downloading the data and uploading new measurement schemes. The second requirement was to measure accurate three-dimensional (3D) positions and behaviour at high temporal resolution and throughout the annual cycle of an individual. We therefore chose to include a 3D GPS receiver for accurate positions, a tri-axial accelerometer to monitor behaviour, and software providing great flexibility for measurement 
schemes that can be changed while the birds are in the air. The third requirement was to limit the weight to a maximum of $12 \mathrm{~g}$, a weight that a medium-sized bird (body weight $300-400 \mathrm{~g}$ ) would be able to carry. This weight restriction mainly limits the number and type of electrical components that we could use, the physical design, the number and size of solar cells and the weight of the battery. As these three main requirements and their solutions are integrated in the design, we structure our description of the bird tracking system according to the three main design components: (1) GPS-tracker, (2) data storage and transmission and (3) data management and services.

\section{GPS-tracker}

To minimize weight, we equipped the tracker with a GPS receiver with a fractal antenna, although the performance of the fractal antenna is generally inferior to that of a heavier ceramic patch antenna. For measurement intervals below $15 \mathrm{~s}$, the GPS receiver is continuously powered; for longer intervals, the GPS receiver is switched on until the position has been fixed. A 3D fix (geographic position and altitude) is acquired if more than three satellites are found by the GPS, and otherwise a 2D fix is stored. The power is supplied by four triple-junction solar cells (27\% efficiency) with a total surface of $9.1 \mathrm{~cm}^{2}$, a loading circuit and a $65 \mathrm{mAh}$ lithium polymer battery. The solar yield, which depends on the size and efficiency of the solar cells, determines the available power in the long run and should enable tracking throughout a bird's annual cycle. The battery capacity determines the size of the buffer required to overcome nights and other periods with little or no solar radiation or periods with high-resolution measurements when more power is used. A $20-\mathrm{Hz}$ tri-axial accelerometer is included in the tracker to monitor body movements, as are temperature and barometric pressure sensors to monitor environmental conditions. The tracker has been designed with the option to include more sensors in the future. The GPS tracker weighs $10 \mathrm{~g}$ plus an additional $2 \mathrm{~g}$ of epoxy coating, and its size is approximately $62 \times 30 \times 12 \mathrm{~mm}$ (Fig. 1). More epoxy, more solar cells and a larger battery can be used if the size and weight do not constitute restrictive factors (e.g. if the GPS tracker weighs far less than $3 \%$ of the bird's mass).

Measurement intervals can be set for different times of the day (e.g. day and night), different geographical areas (e.g. inside or outside a breeding colony), status of memory (e.g. accelerometer is switched-off if the memory is filled to a certain threshold) or battery voltage (e.g. shorter measurement intervals if the battery is fully charged). Thus, the measurement scheme can be dynamically tailored to the specific research questions, the behaviour of the bird species, environmental conditions or tag

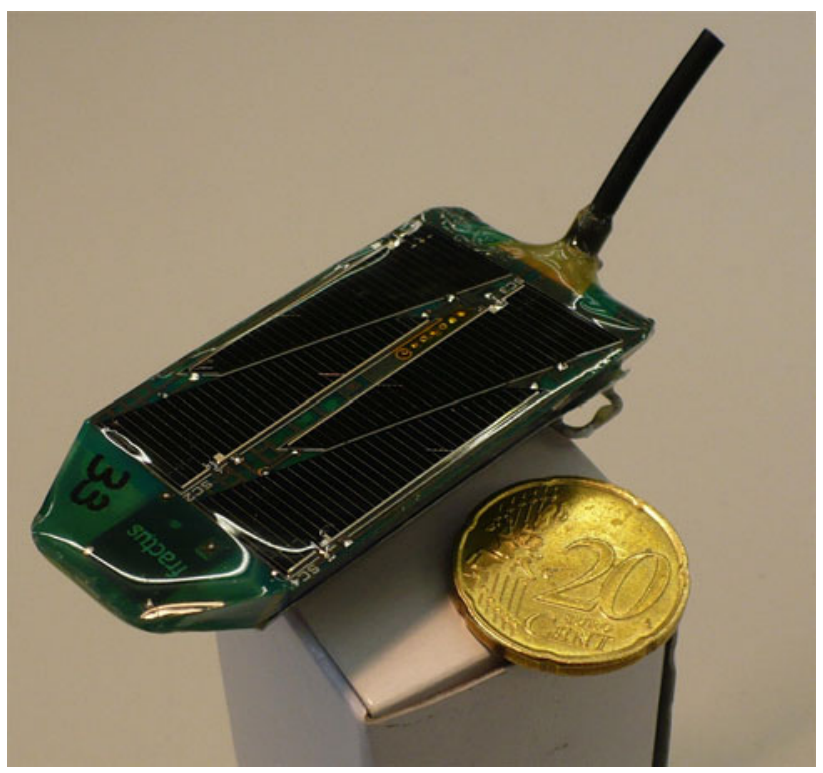

Fig. 1 The tracker with the antenna for wireless communication sticking out at the right-hand side

performance, all of which may change during the course of the season or study.

\section{Data storage and transmission}

Data are stored on the tracker in 4-MB flash memory implemented as a ring buffer. Almost 60,000 GPS records can be stored on the flash memory, including a timestamp, GPS positions and basic information on the battery status. However, if speeds (x,y and $\mathrm{z}$ ) and $3 \mathrm{~s}$ of $20 \mathrm{~Hz}$ accelerometer data are included with every GPS measurement, storage capacity will be filled by about 4,000 GPS entries along with the corresponding accelerometer data. The GPS tracker has a ZigBee transceiver with a 3-cm (1/4 lambda) whip antenna for transmitting the measured data to the base station and for receiving new measurement settings. A ZigBee is a short-range wireless transceiver that, compared to the better known Bluetooth, can handle more sensors, consumes far less power and has a longer transfer range, but at the cost of a lower data transfer rate. If required, the spatial range of communication can be extended with a network of antennas.

\section{Data management and services}

Given the large volume of data gathered, the success of a tracking system is also largely dependent on data management and processing facilities. We therefore developed a Virtual Lab, a cyber-infrastructure based on the research community's needs for optimal information frameworks in tracking studies (Urbano et al. 2010). The Virtual Lab fulfils requirements concerning data scalability, persistent 
storage, data acquisition, retrieval and management, integration of different data sources, data visualization and exploration, data sharing and dissemination, easy implementation of new tools and algorithms, multi-user support and cost-effectiveness. It also facilitates communication to the base station via (mobile) the Internet, to transfer data through Dropbox (www.dropbox.com) or alter measurement schemes at any time and from any location in the world by use of LogMeIn (www.logmein.com). The data are automatically post-processed and persistently stored in a central PostgreSQL spatial database with a web application (phpPgAdmin) to query the data. Summary statistics of the data and tracks that can be visualized in Google Earth are automatically generated. All of this functionality is available through the Virtual Lab portal (www.UvABiTS.nl/virtual-lab).

\section{Test programme}

The potential applications and limitations of a tracking system are determined largely by its measurement performance and the maximum distance for downloading data or uploading new measurement settings. The performance of our GPS tracking system was therefore tested as described below.

\section{GPS tracker performance}

In general, the accuracy of a GPS increases with longer power-up time, shorter intervals between measurements (Mills et al. 2006) and a more open view of the sky (Cargnelutti et al. 2007). As it is almost impossible to obtain reproducible measurements with trackers on birds living in the wild, we tested stationary trackers in open and flat landscape without any physical obstructions to assess accuracies (geographic location, altitude and speed) and the time needed to assess the position (time-to-fix) at measurement intervals of 6,60 and $600 \mathrm{~s}$. The tests were carried out in the same time period of $5 \mathrm{~h}$ with four (6-s interval), eight (60-s interval), and 40 (600-s interval) GPS trackers (1200 measurements for each set). To show the potential impact of habitat properties on tag performance, we compared these measurements with measurements of two contrasting scenarios: (1) measurements at 6-s intervals of a White Stork Ciconia ciconia sitting all night on its nest on a pole in open landscape and (2) measurements at 600 -s intervals of a pair of breeding Honey Buzzards Pernis apivorus on a nest with a known location inside a mixed forest.

With free ranging birds, it is impossible to systematically test all combinations of factors that influence the solar yield and power use and thus the number of measurements that can be made per day. Instead, we selected characteristic examples of measurement schemes from studies with different birds species to discuss what is or is not feasible in terms of measurement frequency.

\section{Data transmission}

The strength of the data transmission link between the GPS tracker and base station depends on the field situation. Generally, the best link between tracker and antenna is obtained with a clear line of sight, in an open field, with the transmitter high in the air and the receiving antenna likewise at high elevation. If either or both are close to the ground, a poor link can result from Fresnel effects (Saunders and Zavala 2007). We tested (1) the maximum data transmission distance between a GPS tracker in a hot air balloon and a ground-based antenna $8 \mathrm{~m}$ above ground level (AGL), (2) the data transmission distance between GPS trackers on birds and the antenna in field experiments and (3) the transmission distance between antennas in two towers at $50 \mathrm{~m}$ AGL.

\section{Monitoring bird movement and behaviour}

To illustrate new opportunities created for ecological and behavioural research at different scales, we present and discuss examples from a Lesser Black-backed Gull Larus fuscus study. The (offshore) foraging behaviour of the Lesser Black-backed Gull is notoriously difficult to study (Camphuysen et al. 2012). We show the details of a foraging trip in the breeding season using accelerometer and speed data to classify behaviour (Shepard et al. 2008; Shamoun-Baranes et al. 2012). We also present GPS data measured during migration and in the winter season.

\section{Results}

\section{GPS tracker performance}

The test of the stationary GPS tracker in open landscape and clear sky with a 6-s measurement interval shows a positional mean error of only $1.13 \mathrm{~m}$, with 0.05 and 0.95 quantiles of the measured cumulative error distribution of 0.2 and $2.33 \mathrm{~m}$, respectively (Table 1). The mean altitude error and 0.05 and 0.95 quantiles are somewhat higher, and instantaneous speeds in 3D and in the horizontal plane (2D) deviate slightly from the true speed of $0.00 \mathrm{~m} / \mathrm{s}$. At the 6-s interval, the GPS receiver uses almost all of the available time in between fixes to determine its position before starting the next measurement (mean 5.29 s) and uses up to nine satellites. All fixes are 3D fixes. The errors of position, altitude and speed clearly increase with an increased measurement interval (Table 1). With an 
increased measurement interval, the receiver is turned off between two sequential measurements (at intervals $>15 \mathrm{~s}$ ); consequently, the time to fix also increases and the number of satellites decreases. In all cases, fixes are always 3D fixes. The errors of position, altitude and speed of the GPS measurements of the White Stork while on its nest are similar to or only slightly larger than the stationary measurements. When comparing the Honey Buzzard measurements with the unobstructed measurements at 600-s intervals, the effects of the canopy are demonstrated as a larger position error and a longer time-to-fix, with fewer satellites in view and lower fix success. On occasion, the fix could not be made in the maximum time of $100 \mathrm{~s}(7 \%$ of the trials) or only three satellites were found within the available time and thus only $2 \mathrm{D}$ positions could be determined ( $9 \%$ of the trials). Summarizing these experiments, we conclude that the tracker with fractal antenna performs as well as other GPS devices with larger and heavier antennas (Sager-Fradkin et al. 2007), even under a forest canopy.

Table 2 shows that on a sunny day in the summer (daily cumulative solar radiation $2,500 \mathrm{~J} / \mathrm{cm}^{2}$ ) almost 7,000 measurements were obtained on a White Stork without depleting the battery (18-g tracker with $240 \mathrm{mAh}$ battery). However, for prolonged monitoring without gaps in the data, with no alteration of settings, 192 measurements per day were feasible in July for the Lesser Black-backed Gull and 106 per day for the Honey Buzzard, as power consumption is higher and solar yield lower in forests than open landscapes (Table 1). During the winter, the number of measurements per day was very limited (approximately 15 per day) on the Oystercatcher Haematopus ostralegus in The Netherlands, as mean daily solar radiation in December is ninefold lower than in July (KNMI 2011). The numbers that are presented in Table 2 provide an impression of the restrictions in measurement schemes due to limited solar radiation over the year. The possibility of altering the settings according to expected solar radiation is thus of crucial importance for optimizing measurement schemes in year-round studies of free-ranging animals and multi-scale research.

\section{Data transmission}

The maximum data transmission distance, obtained with a clear line of sight, was $8.5 \mathrm{~km}$ between a GPS tracker under the hot air balloon at an altitude of $190 \mathrm{~m}$ and the ground-based antenna at $8 \mathrm{~m}$ AGL. However, with Oystercatchers walking on a salty mud flat and the antenna at about $8 \mathrm{~m}$ AGL a link was sometimes problematic, even at a distance of only $1 \mathrm{~km}$, due to Fresnel and waveguide effects, which attenuate the signal, being stronger on salty mud flats than on dry sandy soils. Inside a coniferous 
Table 2 Examples of maximum number of measurements per day for four bird species under various conditions of solar radiation

\begin{tabular}{|c|c|c|c|c|}
\hline Species & $\begin{array}{l}\text { GPS intervals } \\
(\text { day/night, s })^{\mathrm{a}}\end{array}$ & $\begin{array}{l}\text { Daytime interval } \\
(\mathrm{GMT})^{\mathrm{b}}\end{array}$ & $\begin{array}{l}\text { Measurements } \\
(n / \text { day })^{\mathrm{c}}\end{array}$ & $\begin{array}{l}\text { Solar radiation } \\
\left(\mathrm{J} / \mathrm{cm}^{2} / \text { day }\right)^{\mathrm{d}}\end{array}$ \\
\hline White Stork & $3 / 3,600$ & $1100-1600$ hours & 6,958 & $2,500^{\mathrm{e}}$ \\
\hline Lesser Black-backed Gull & 450 & 0000-2400 hours & 192 & $1,700^{\mathrm{f}}$ \\
\hline Honey Buzzard & $600 / 7200$ & 0430-2130 hours & 106 & $1,700^{\mathrm{f}}$ \\
\hline Oystercatcher & $3,600 / 14,400$ & 0600-2400 hours & 15 & $190^{\mathrm{g}}$ \\
\hline \multicolumn{5}{|c|}{${ }^{a}$ GPS measurement intervals (s) during the day and at night (day/night) } \\
\hline \multicolumn{5}{|c|}{ b Time range (GMT) for daytime intervals } \\
\hline \multicolumn{5}{|c|}{${ }^{c}$ Mean number of measurements per day } \\
\hline \multicolumn{5}{|c|}{$\begin{array}{l}\text { d Characteristic solar radiation when the measurements were taken. Data provided by the Royal Netherlands Meteorological Institute (KNMI } \\
\text { 2011) }\end{array}$} \\
\hline \multicolumn{5}{|c|}{ e Typical solar radiation on a day with a clear sky in June } \\
\hline \multicolumn{5}{|l|}{${ }^{\mathrm{f}}$ Mean in July } \\
\hline Mean in December & & & & \\
\hline
\end{tabular}

forest, the link between tracker and antenna was only $300 \mathrm{~m}$, as the transmission signal was attenuated by such obstacles as bushes and trees. For a study on foraging behaviour of the Honey Buzzard we needed six antennas in tree tops to create a network covering the study area of about $50 \mathrm{~km}^{2}$. In the test with two directional antennas at $50 \mathrm{~m}$ AGL in power line towers in a flat polder landscape with sparsely distributed trees, we established a link of $40 \mathrm{~km}$. These data reveal that the optimal antenna configuration of the network depends on the landscape, the home range and activity of the species being studied and on the need for contact if a frequent change in the measurement scheme or frequent data download is desired.

\section{Monitoring bird movement and behaviour}

Here we highlight movements and behaviour that have been measured as an example to show how a flexible bird tracking system can advance behavioural and ecological studies.

Figure 2 shows a 260-km foraging trip (900 GPS measurements) of a Lesser Black-backed Gull on a sunny day. A breeding female (ring FAKV, Id 355) left the colony on the island Texel at 0100 hours, paused to float in the Wadden Sea for $1 \mathrm{~h}$ (Shamoun-Baranes et al. 2011), then used flapping flight to the mainland and foraged for several hours in agricultural fields and in the village of Hoorn, following which the bird flew towards Amsterdam using flapping flight. These different behaviours can be easily identified from the patterns of tri-axial acceleration (inset in Fig. 2). From 0700 hours UTC onward, the earth surface apparently produced warm rising air and the bird changed its flight strategy from flapping to soaring flight. Once it reached Amsterdam, it spent $25 \mathrm{~min}$ in one of the canals and then headed to north again while alternating soaring (up to maximum altitudes of $980 \mathrm{~m}$ AGL) and gliding until it reached the coast. Above the North Sea it continued the trip with flapping flight, interspersed with short bouts of soaring and floating on the water. At 1430 hours it started flying back to the colony where it arrived at 1645 hours. Many more details can be seen by interactively using a kmz-file that is provided in the Electronic Supplementary Material (ESM). The information collected on a trip such as this can, for example, be used to estimate flight costs (from a combination of distance travelled, flight behaviour and weather conditions) and to pinpoint particular foraging areas.

Lesser Black-backed Gulls are migratory birds, wintering mainly in France, on the Iberian Peninsula or in NW Africa. While both the migration routes and the final destinations have been documented with ringing studies and satellite transmitters (Klaassen et al. 2012), the details of flight strategies and time-budgets of migrants are still largely unknown.

Figure $3 \mathrm{a}$ shows the migration routes and movements during the wintering season of a male Lesser Black-backed Gull (ring MAMM, Id317) over 2 sequential years. The GPS tracker revealed the timing of departure (25 July 2010 and 28 July 2011, respectively), stop-over use in northern France (30 July-10 October 2010 and 28 July-29 October 2011, respectively), routes across the Bay of Biscay and around the Iberian Peninsula (Portuguese coast) on the way south (Fig. 3a), a wintering period mainly in the south of Spain (Fig. 3b), and frequenting of the rice fields north of Donãna National park, the Costa del Sol, and garbage dumps (Fig. 3c). The return flights started 15 March 2011 and 04 March 2012, respectively, with a direct line through Spain, across the Bay of Biscay to The Netherlands (arrival 30 March 2011 and 23 March 2012, respectively). The total travelled distance, including autumn and spring migration 


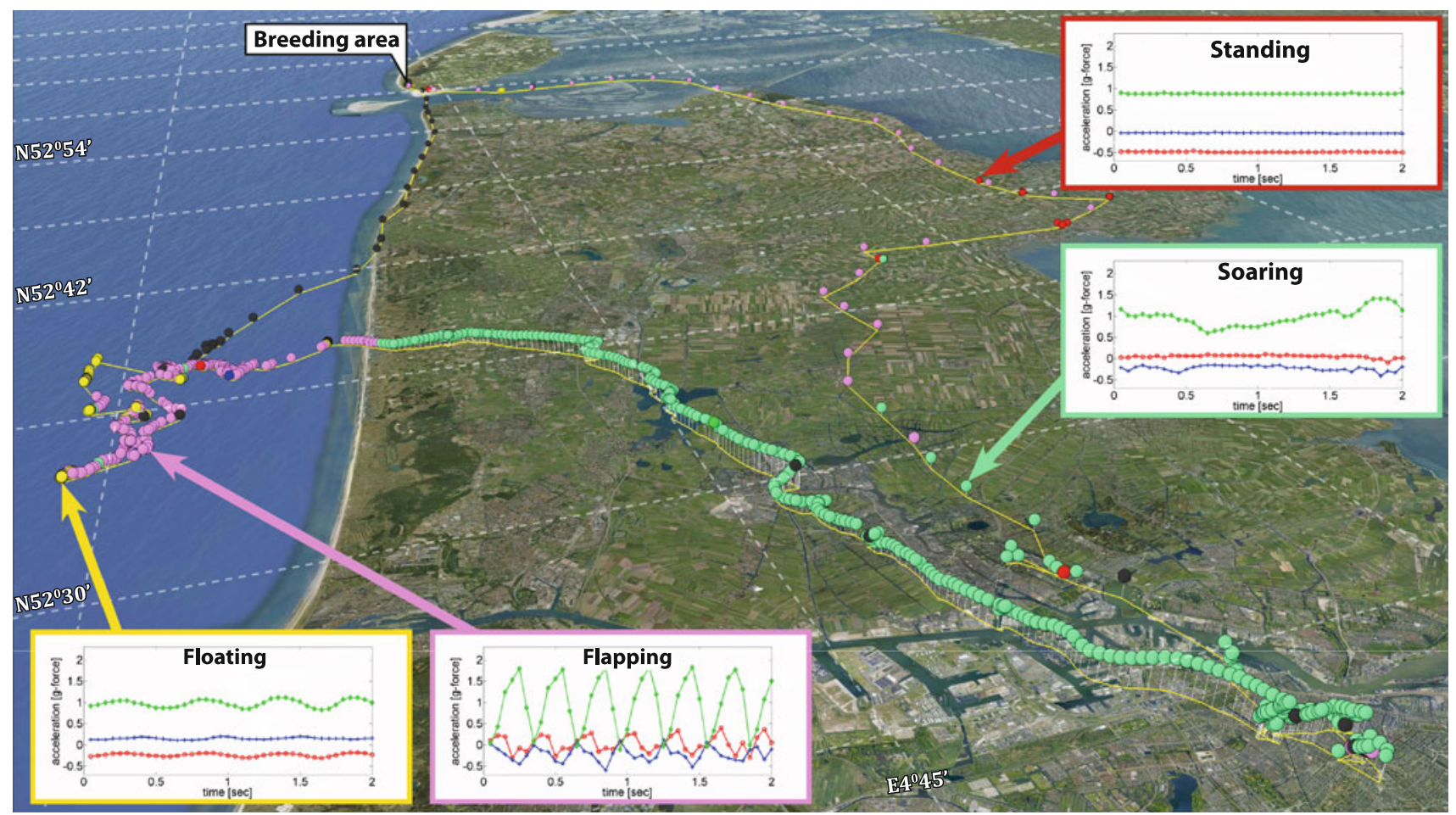

Fig. 2 A foraging flight of a Lesser Black backed Gull (28 June 2010, 01:03:53-16:41:47). Each point represents a GPS location, while the colours represent the behaviour (pink flapping flight, red stand or walk, green soaring or gliding flight, yellow floating at sea, gray no accelerometer data or not classified). For these behaviours, the insets show characteristic patterns of the tri-axial accelerometer

and local movements at the wintering grounds, was $20,817 \mathrm{~km}$, monitored with 12,385 GPS-points $(22,331 \mathrm{~km}$ with 12,216 GPS-points in the next year). The resolution of the collected data is such that time budgets can be calculated. In the winter of 2010/2011 the bird visited three different habitats, spending $43 \%$ of the time in rice fields, $44 \%$ in landfill areas and $7 \%$ at the Costa del Sol. In the next season, the wintering time budget indicated a more frequent use of landfill sites (25\% rice fields, $55 \%$ garbage dump area, $13 \%$ Costa del Sol). Multi-scale movements are difficult to show in a static figure. Many more details can be revealed with the Google Earth kmz-files that are provided in the ESM.

\section{Discussion}

The examples from an ongoing Lesser Black-backed Gull study show that unprecedented details of an individual's behaviour can be revealed throughout its annual routine, during local foraging movements in the breeding season, migration and foraging movements in over-wintering areas. From high-resolution measurements combined with accelerometer data, as presented in Fig. 2, we were able to with time shown on the $x$-axis and the acceleration, expressed in units of $\mathrm{g}$-force $\left(1 \mathrm{~g}=9.81 \mathrm{~m} / \mathrm{s}^{2}\right)$, shown on the $y$-axis, with heave shown (filled circle) in green, surge (open circle) in red and sway (plus symbol) in blue. A kmz-file for interactive exploration of the data is provided in the ESM

determine flight strategies and calculate climb rates and gliding angles during soaring flight. The integration of GPS and accelerometer measurements with data on atmospheric dynamics (Shamoun-Baranes et al. 2010; Mandel et al. 2011; Shepard et al. 2011) and detailed simulation models (van Loon et al. 2011) creates new opportunities for understanding how birds are influenced by and adapt their behaviour to the dynamic ambient environment. Moreover, the combination of GPS and accelerometer provides the means to calculate and merge information on time budgets, foraging strategies and efficiency, resource use and energy expenditure (Ropert-Coudert and Wilson 2005; Gleiss et al. 2011; Shamoun-Baranes et al. 2012). In the long run this will contribute to a better understanding of breeding success, chick growth and population dynamics in general.

The development of a bird tracker is generally based on a compromise balancing the weight of the device and the amount and quality of the data generated. We expect that geolocators, currently produced as light as $0.5 \mathrm{~g}$ (Egevang et al. 2010), will always outcompete GPS-devices in terms of weight. Although extremely useful for smaller birds, their use is mainly limited to a rough estimate of migration routes and timing because of the poor spatial accuracy and low temporal resolution of these devices (Bridge et al. 


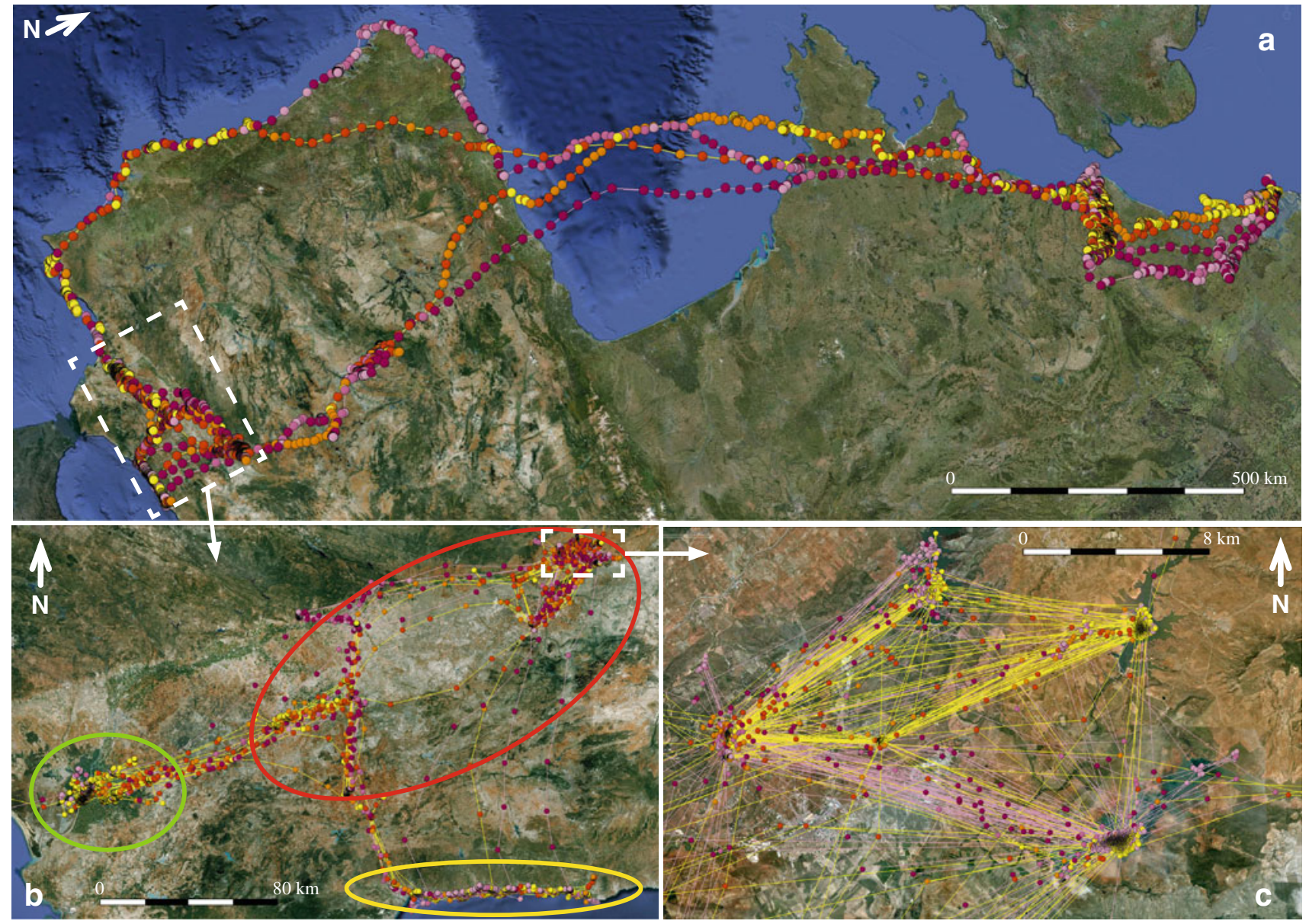

Fig. 3 a Migration and wintering movements of a Lesser Blackbacked Gull in 2010-2011 (yellow) and 2011-2012 (pink). Flight speed classes range from $<1 \mathrm{~m} / \mathrm{s}$ (lightest colour) through to $1-3$, 3-10 and $>10 \mathrm{~m} / \mathrm{s}$ (darkest colour). The wintering area in Spain within the white dashed rectangle is enlarged in $\mathbf{b}$. $\mathbf{b}$ The roosting and

2011). The GPS-tracker that is described in this paper has an incomparably higher spatial accuracy and temporal resolution, but it weighs $12 \mathrm{~g}$ and can therefore only be deployed on medium-sized and larger birds.

Our choice for communication through a local antenna network has large implications. GSM or satellite communication would have been easier for the user, but these consume much more energy and would thus require larger solar panels and batteries. Our solution means that more effort is needed to set up the antenna or even a network of antennas and that researchers must wait until a bird returns to the area to retrieve data remotely. However, the bidirectional communication has been shown to be a key advantage of the system; it can easily download the large amounts of data that come with high-resolution GPS measurements and accelerometer, and it increases the flexibility as the researcher can adjust the measurement program to cater for specific research objectives, without having to recapture the bird. foraging sites are rice fields (green ellipse), garbage dumps and lakes (red ellipse) and the Costa del Sol (yellow ellipse). The area within the white dashed rectangle (b) is enlarged in c. c The commuting between foraging and roost sites. Kmz-files for interactive exploration of the data are provided in the ESM

\section{Concluding remarks}

As technological constraints do not allow the development of 'the ultimate optimal system' described earlier, we have developed and tested a next-generation GPS tracking system which at least reflects some of the most important criteria and is suitable for a broad range of tracking studies.

The choice for a solar-powered device with flexible measurement schemes that can be changed remotely has dramatically increased the feasible number of measurements. It enables studies of behaviour and movement at different spatial and temporal scales throughout the entire annual routine of a free ranging bird. The results presented here should be considered as a snapshot within a trajectory of continuous developments of tracking devices and biologgers. Past trends in electronics, batteries and solar cells, however, suggest that a $50 \%$ reduction of weight and size will be possible every few years for a GPS-tracker with roughly the same functions. Four years after our first 
prototype tracker of $12 \mathrm{~g}$, we are now testing a prototype which only weighs $6 \mathrm{~g}$.

In our GPS tracking system we have merged the strengths of the GPS for tracking, the accelerometer for monitoring behaviour and a virtual lab to work with the data, while the next challenge will be to add tiny environmental and physiological sensors. We produce these systems for our partners in collaborative research. Several recent papers have pointed at the exciting new opportunities that are created by technological innovations (Wikelski et al. 2007; Robinson et al. 2010; Guilford et al. 2011). Innovations in electronics will help answer our current research questions and generate new ones, which in turn will result in new system requirements and future developments. Over the next 10 years we expect these developments to further revolutionize research on animal behaviour and ecology.

Acknowledgments For the development of our GPS tracker a grant was obtained from the Hertzberger Fund of the University of Amsterdam. In addition, our bird migration studies were supported by the BiG Grid infrastructure for eScience (http://www.biggrid.nl). We thank all our collaborators who have captured birds, deployed the devices, done field work and provided feedback during the first 3 years of field testing: R. Bom, I. Both, O. Duriez, B. Ens, A. Gronert, B. Koks, F. Majoor, R. Nathan, K. Oosterbeek, Y. Orchan, A. Román, M. Roodbergen, J. van Diermen, I. van Lanen, W. van Manen, C. Thaxter, B. Toxopeus and W. van Stralen. Moreover, B. Heupers, T. de Kler, L. Voort of SARA Computing and Networking Services and A. J. van der Linden are thanked for their contributions to the development of the Virtual Lab. Our experiments comply with the current laws of the Netherlands.

Open Access This article is distributed under the terms of the Creative Commons Attribution License which permits any use, distribution, and reproduction in any medium, provided the original author(s) and the source are credited.

\section{References}

Bridge ES, Thorup K, Bowlin MS, Chilson PB, Diehl RH, Fléron RW, Hartl P, Kays R, Kelly JF, Robinson WD, Wikelski M (2011) Technology on the move: recent and forthcoming innovations for tracking migratory birds. Bio Sci 61:689-698

Cagnacci F, Boitani L, Powell RA, Boyce MS (2010) Animal ecology meets GPS-based radiotelemetry: a perfect storm of opportunities and challenges. Phil Trans R Soc B 365:2157-2162

Camphuysen CJ, Shamoun-Baranes J, Bouten W, Garthe S (2012) Identifying ecologically important marine areas for seabirds using behavioural information in combination with distribution patterns. Biol Conserv. doi:10.1016/j.biocon.2011.12.024

Cargnelutti B, Coulon A, Hewison AJM, Goulard M, Angobault JM, Morellet N (2007) Testing global positioning system performance for wildlife monitoring using mobile collars and known reference points. J Wildl Manag 71:1380-1387

Casper RM (2009) Guidelines for the instrumentation of wild birds and mammals. Anim Behav 78:1477-1483
Cooke SJ, Hinch SG, Wikelski M, Andrews RD, Kuchel LJ, Wolcott TG, Butler PJ (2004) Biotelemetry: a mechanistic approach to ecology. Trends Ecol Evol 19:334-343

Egevang C, Stenhouse IJ, Phillips RA, Petersen A, Fox JW, Silk JRD (2010) Tracking of Arctic terns Sterna paradisaea reveals longest animal migration. Proc Natl Acad Sci USA 107: 2078-2081

Gleiss AC, Wilson RP, Shepard ELC (2011) Making overall dynamic body acceleration work: on the theory of acceleration as a proxy for energy expenditure. Methods Ecol Evol 2:23-33

Guilford T, Akesson S, Gagliardo A, Holland RA, Mouritsen H, Muheim R, Wiltschko R, Wiltschko W, Bingman VP (2011) Migratory navigation in birds: new opportunities in an era of fast-developing tracking technology. J Exp Biol 214:37053712

Klaassen RHG, Ens BJ, Shamoun-Baranes J, Exo KM, Bairlein F (2012) Migration strategy of a flight generalist, the Lesser Blackbacked Gull Larus fuscus. Behav Ecol 23(1):58-68. doi:10.1093/ beheco/arr150

KNMI (Royal Netherlands Meteorological Institute) (2011) Available at: http://www.knmi.nl/klimatologie/maand_en_seizoensoverzichten/ index.html Accessed 2 Jun 2012

Mandel J, Bohrer G, Winkler D, Barber D, Houston C, Bildstein K (2011) Migration path annotation: cross-continental study of migration-flight response to environmental conditions. Ecol Appl 21:2258-2268

Mills KJ, Patterson BR, Murray DL (2006) Effects of variable sampling frequencies on GPS transmitter efficiency and estimated wolf home range size and movement distance. Wildl Soc Bull 34:1463-1469

Robinson WD, Bowlin MS, Bisson I, Shamoun-Baranes J, Thorup K, Diehl RH, Kunz TH, Mabey S, Winkler DW (2010) Integrating concepts and technologies to advance the study of bird migration. Front Ecol Environ 8:351-361

Ropert-Coudert Y, Wilson RP (2005) Trends and perspectives in animal-attached remote sensing. Front Ecol Environ 3:437-444

Rutz C, Hays GC (2009) New frontiers in biologing science. Biol Lett 5:289-292

Sager-Fradkin KA, Jenkins KJ, Hoffman RA, Happe PJ, Beecham JJ, Wright RG (2007) Fix success and accuracy of Global Positioning System collars in old-growth temperate coniferous forests. J Wildl Manag 71:1298-1308

Saunders SA, Zavala AA (2007) Antennas and propagation for wireless communication systems. Wiley, Hoboken. ISBN 978-0470-84879-1

Shamoun-Baranes J, Bouten W, van Loon EE (2010) Integrating meteorology into research on migration. Integr Comp Biol 50: 280-292

Shamoun-Baranes J, Bouten W, Camphuysen CJ, Baaij EW (2011) Riding the tide: intriguing observations of gulls resting at sea during breeding. Ibis 153:411-415

Shamoun-Baranes J, Bom R, van Loon EE, Ens BJ, Oosterbeek K, Bouten W (2012) From sensor data to animal behaviour: an oystercatcher example. PLoS ONE 7(5):e37997. doi:10.1371/ journal.pone.0037997

Shepard ELC, Wilson RP, Quintana F, Gómez Laich A, Liebsch N, Albareda DA, Halsey LG, Gleiss A, Morgan DT, Myers AE, Newman C, Macdonald DW (2008) Identification of animal movement patterns using tri-axial accelerometry. Endanger Species Res 10:47-60

Shepard ELC, Lambertucci SA, Vallmitjana D, Wilson RP (2011) Energy beyond food: foraging theory informs time spent in thermals by a large soaring bird. PLoS ONE 6:e27375

Sokolov LV (2011) Modern telemetry: new possibilities in ornithology. Biol Bull 38(9):885-904 
Tomkiewicz SM, Fuller MR, Kie JG, Bates KK (2010) Global positioning system and associated technologies in animal behaviour and ecological research. Phil Trans R Soc B 365: 2163-2176

Urbano F, Cagnacci F, Calenge C, Dettki H, Cameron A, Neteler M (2010) Wildlife tracking data management: a new vision. Phil Trans R Soc B 365:2177-2185
Van Loon EE, Shamoun-Baranes J, Bouten W, Davis SL (2011) Understanding soaring bird migration through interactions and decisions at the individual level. J Theor Biol 270:112-126

Wikelski M, Kays RW, Kasdin NJ, Thorup K, Smith JA, Swenson GW Jr (2007) Going wild: what a global small-animal tracking system could do for experimental biologists. J Exp Biol 210: $181-186$ 